Mammography and MRI for screening women who underwent chest radiation therapy (lymphoma survivors). Recommendations for surveillance from the Italian College of Breast Radiologists by SIRM

Mariscotti $\mathrm{G}^{1}$, Belli $\mathrm{P}^{2}$, Bernardi $\mathrm{D}^{3}$, Brancato $\mathrm{B}^{4}$, Calabrese $\mathrm{M}^{5}$, Carbonaro $\mathrm{A}^{6}$, Cavallo-Marincola $\mathrm{B}^{7}$, Caumo $\mathrm{F}^{8}$, Clauser $\mathrm{P}^{9,10}$, Martincich $\mathrm{L}^{11}$, Montemezzi $\mathrm{S}^{12}$, Panizza $\mathrm{P}^{13}$, Pediconi $\mathrm{F}^{7}$, Tagliafico $\mathrm{A}^{14}$, Trimboli $\mathrm{RM}^{6}$, Zuiani $\mathrm{C}^{10}$, Sardanelli $\mathrm{F}^{6,15}$

1 Radiologia 1U, Dipartimento di Diagnostica per Immagini, Università di Torino, A. O. U. Città della Salute e della Scienza di Torino, Via Genova, 3, 10126 Torino

2 Dipartimento di Scienze Radiologiche, Università Cattolica del Sacro Cuore, Largo Agostino Gemelli, 8, 0168 Roma

3 U.O. Senologia Clnica e Screening Mammografico, Dipartimento di Radiologia, APSS, Centro per i Servizi Sanitari, Pal. C, viale Verona, 38123 Trento

4 Istituto per lo Studio e la Prevenzione Oncologica (ISPO), Via Cosimo il Vecchio, 2, 50139 Firenze

5 UOC Senologia Diagnostica, IRCCS AOU San Martino-IST, Largo Rosanna Benzi, 10, 16132 Genova

6 Unit of Radiology, IRCCS Policlinico San Donato, Via Morandi, 30, 20097, San Donato Milanese, Milano

7 Dipartimento di Scienze Radiologiche, Oncologiche ed Anatomo-patologiche, Policlinico Umberto I, Sapienza Università di Roma, Viale Regina Elena, 324, 00161, Roma

8 UOSD Breast Unit ULSS20, Piazza Lambranzi, 1, 37142 Verona

9 Department of Biomedical Imaging and Image-guided Therapy, Division of Molecular and Gender Imaging Medical University of Vienna/ General Hospital Vienna, Waehringer Guertel 18-20, 1090 Vienna, Austria

10 Institute of Radiology, University of Udine, p.le S. M. della Misericordia, 15, 33100 Udine

11 Unit of Radiology, Institute for Cancer Research and Treatment (IRCC)-FPO, 10060 Candiolo, Torino

12 DAI Patologia e Diagnostica, Azienda Ospedaliera Universitaria Integrata, P.le A. Stefani, 1, 37126 Verona

13 U.O. Radiologia Senologica, IRCCS Ospedale San Raffaele, Via Olgettina, 60, 20132 Milano 
Department of Experimental Medicine, DIMES, Institute of Anatomy, University of Genova, Via de Toni, 14, 16132 Genova

15 Università degli Studi di Milano, Dipartimento di Scienze Bi, Via Morandi 30, 20097 San Donato Milanese, Milano

Corresponding Author:

Prof. Francesco Sardanelli

Department of Biomedical Sciences for Health, Università degli Studi di Milano

Unit of Radiology, IRCCS Policlinico San Donato

Via Morandi 30, 20097 San Donato Milanese, Milano

Tel +390252774626; Fax +390252774695

E-mail: francesco.sardanelli@unimi.it 


\section{Mammography and MRI for screening women who underwent chest radiation therapy (lymphoma survivors). Recommendations for surveillance from the Italian College of Breast Radiologists by SIRM}

\section{Abstract}

Women who underwent chest radiation therapy (CRT) during pediatric/young-adult age (typically lymphoma survivors) have an increased breast cancer (BC) risk, in particular for high doses. The cumulative incidence from 40 to 45 years of age is $13-20 \%$, similar to that of BRCA mutation carriers for whom contrast-enhanced magnetic resonance imaging (MRI) is recommended. However, in women who underwent CRT, MRI sensitivity is lower (63-80\%) and that of mammography is higher (67-70\%) than those observed in women with hereditary predisposition, due to a higher incidence of ductal carcinoma in situ with microcalcifications and low neoangiogenesis. A sensitivity close to $95 \%$ can be obtained only using mammography as an adjunct to MRI. Considering the available evidence, women who underwent CRT before 30 receiving a cumulative dose $\geq 10$ Gy should be invited after 25 (or, at least, 8 years after CRT) to attend the following program: 1 . Interview about individual risk profile and potential of breast imaging; 2 . Annual MRI using the same protocol recommended for women with hereditary predisposition; 3 . Annual bilateral 2-view full-field digital mammography or digital breast tomosynthesis (DBT) with synthetic 2D reconstructions. Mammography and MRI can be performed at once or alternate, every 6 months. In the case of MRI or contrast material contraindications, ultrasound will be performed instead of MRI. Reporting using BI-RADS is recommended. When reaching the age for entering population screening, the individual risk profile will be discussed with the woman to opt for the only mammography/DBT screening or for continuing the intensive protocol.

\section{Riassunto}

Le donne sottoposte a radioterapia toracica (RTT) in età pediatrica o giovane-adulta, tipicamente per linfoma di Hodgkin, hanno un rischio aumentato di sviluppare tumore mammario (TM), in particolare quelle 
trattate con RTT ad alte dosi. L'incidenza cumulativa di TM tra 40 e 45 anni è del 13-20\%, simile a quella delle donne BRCA mutate, per le quali è ormai consolidata l'indicazione alla risonanza magnetica (RM) con mezzo di contrasto (MdC) annuale. Tuttavia, rispetto agli studi di screening delle donne ad elevato rischio eredo-familiare, nelle donne sottoposte a RTT si è osservata una sensibilità relativamente maggiore della mammografia e relativamente minore della RM con MdC, correlate alla maggiore incidenza di carcinoma duttale in situ con microcalcificazioni e minore neoangiogenesi. Sulla base dell'evidenza disponibile, le donne sottoposte a RTT prima dei 30 anni di età con dose cumulativa $\geq 10$ Gy dovrebbero essere invitate a partire dai 25 anni o almeno da 8 anni dopo la RTT a partecipare a un programma di sorveglianza che preveda: 1. colloquio informativo finalizzato all'informazione della donna sul proprio livello di rischio correlato alla RTT e ad eventuali altri fattori e sul potenziale delle tecniche di imaging; 2 . RM con MdC bilaterale annuale con il medesimo protocollo raccomandato per lo screening delle donne ad elevato rischio eredo-familiare; 3. mammografia digitale bilaterale annuale o tomosintesi con ricostruzioni 2D (proiezioni cranio-caudale e medio-laterale obliqua). Mammografia e RM possono essere eseguite contestualmente o alternate a cadenza semestrale. Reperti ed indagini mammografiche e RM saranno classificati secondo la scala categoriale BI-RADS. Nel caso di controindicazioni alla RM o alla somministrazione di MdC paramagnetico, sarà eseguita ecografia mammaria bilaterale anche in presenza di mammografia negativa, contestualmente alla mammografia o con alternanza semestrale. Al raggiungimento dell'età per l'invito ai programmi di screening organizzato, il profilo di rischio della donna sarà rivalutato e discusso al fine di decidere se optare per l'adesione al protocollo di screening basato su mammografia (eventualmente tomosintesi) annuale o biennale o per la prosecuzione dello screening intensivo con mammografia e RM annuali. Si raccomanda che il presente protocollo di sorveglianza sia effettuato presso centri di radiologia senologica che rispettino i requisiti quali/quantitativi definiti da lineeguida internazionali e che tutti i dati relativi all'applicazione del protocollo, ivi compresi i cancri d'intervallo, siano raccolti mediante database informatizzato al fine di consentire analisi di performance diagnostica e di efficacia su scala multicentrica. 


\section{Background and rationale}

Women who underwent chest radiation therapy (CRT) during pediatric/young-adult age (typically those treated for Hodgkin lymphoma) have an increased breast cancer (BC) risk, in particular those who received mantle CRT with high doses. However, an increased risk is also associated with RT with moderate doses for non-Hodgkin lymphoma, Wilms tumor, leukemia, bone tumors, neuroblastoma or soft tissue sarcoma [1]. The cumulative BC incidence from 40 to 45 years of age in women who underwent CRT is $13-20 \%$, higher than the incidence observed in the young female general population and similar to that of BRCA mutation carriers $[1,2]$. The age at which CRT was performed and the radiation dose impact on the risk, higher for high doses delivered between 10 and 16 years of age. The $B C$ is diagnosed on average about 15 years after CRT at about 40 [3], to be compared with a mean age of about 61 in the general female non-exposed population [1]. Breast cancers in women who underwent CRT are similar to those we encounter in the general female population in regard to histopathologic subtype, receptor status, lymphatic invasion and nodal involvement, which play in favor of a potential role of early diagnosis. Conversely, BCs in women who underwent CRT exhibit a preferential localization at upper external quadrants more extreme than that observed in women with hereditary predisposition (67\% versus $48 \%$, respectively). Moreover, in these women the possibilities of treatment of $\mathrm{BC}$ mostly exclude radiation therapy and chemotherapy with doxorubicin [4].

For women who underwent CRT, international guidelines $[2,5,6]$ recommend annual mammography and contrast-enhanced magnetic resonance imaging (MRI), starting from 25 years of age or, for those women who had CRT before 30, 8 years after the end of treatment. The rationale is the similar $\mathrm{BC}$ incidence in the young age for women who had CRT and women with hereditary predisposition associated with relatively lower sensitivity of mammography, also related to the need to start at a young age, and higher sensitivity of MRI [7].

The availability and application of guidelines/recommendations for the surveillance of women who underwent CRT is relevant for good clinical practice. In fact, BC risk of these women and, as a consequence, the importance of breast surveillance is frequently underestimated. In the United States, a study published 
in 2009 [8] reported that, of 551 women with previous CRT, $47 \%$ of those with $25-39$ years of age never had a mammogram and only $37 \%$ had biannual screening mammography, the same percentages being $8 \%$ and $53 \%$ between 40 and 50 years of age. Importantly, the screening rate was higher in the presence of a specific medical recommendation. The last point highlights the need for clear statements from medical bodies.

Before the MRI introduction, the breast surveillance of women with previous CRT included annual physical examination and mammography [9]. This protocol allowed for detecting $60 \%$ of $\mathrm{BC}$ in the preinvasive phase or at T1 stage $[10-14]$. Two prospective $[15,16]$ and two retrospective studies $[17,18]$ compared mammography and MRI. Sensitivity ranged from $67 \%$ to $70 \%$ for mammography, from $63 \%$ to $80 \%$ for MRI, with a $92 \%$ sensitivity reached only in one retrospective study, with a very small sample size for MRI [18]. Importantly, in women who underwent CRT, MRI sensitivity is relatively lower (63-80\%) and that of mammography is relatively higher (67-70\%) than those observed in women with hereditary predisposition, due to a higher incidence of ductal carcinoma in situ with microcalcifications [19] and low neoangiogenesis. A sensitivity close to $95 \%$ can be obtained only using mammography as an adjunct to MRI.

An expert panel [20] recently compared the recommendations proposed by the following working groups: North American Children's Oncology Group (COG), Dutch Childhood Oncology Group (DCOG), Scottish Intercollegiate Guidelines Network (SIGN), and UK Children's Cancer and Leukaemia Group (UKCCLG). As a result of this comparison, a series of "harmonized recommendations" were provided: physicians, health care providers, and the women who had CRT should be informed on the treatmentrelated $\mathrm{BC}$ risk (strong recommendation); the surveillance is recommended for doses $\geq 20 \mathrm{~Gy}$ (strong recommendation); the surveillance is reasonable for doses between 10 and $19 \mathrm{~Gy}$, taking into account the clinical context and further risk factors (moderate recommendation); the surveillance may be reasonable for doses between 1 and $9 \mathrm{~Gy}$, taking into account the clinical context and further risk factors (weak recommendation); the surveillance implies annual check from 25 years of age or, at least, 8 years after CRT up to 50 years of age using mammography, MRI or both of them (strong recommendation); physical 
examination may be reasonable in countries where only clinical surveillance is available (weak recommendation).

\section{Recommendations for breast surveillance of women who underwent CRT}

Considering the available evidence, women who underwent CRT before 30 receiving a cumulative dose $\geq 10$ Gy should be invited after 25 (or, at least, 8 years after CRT) to attend the following program:

1. dedicated interview about individual risk profile and potential of different breast imaging modalities in this specific setting according this document or other recommendations [5,6,21-23];

2. annual contrast-enhanced MRI using the same protocol recommended for women with hereditary predisposition [2, 23];

3. annual bilateral 2-view full-field digital mammography or digital breast tomosynthesis (DBT) with synthetic 2D reconstructions.

Mammography and MRI can be performed at once (preferably during only one visit) or alternated, every 6 months, in relation with local conditions. Reporting using BI-RADS [24] for individual findings and overall is recommended. In the case of BI-RADS diagnostic category 1 o 2 after MRI plus mammography, the woman will be sent to the next screening event, taking in considerations the lack of evidence in favor of ultrasound if both MRI and mammography are negative. In the case of BI-RADS $\geq 3$, the radiologist will evaluate which work-up is needed, including additional mammographic views, DBT (if not already performed), ultrasound, imaging-guided core or vacuum-assisted needle biopsy.

When reaching the age for entering population screening program, the individual risk profile will be discussed with the woman to opt for the only mammography/DBT screening or for continuing the intensive protocol including MRI.

We strongly recommend that this surveillance protocol is conducted at breast imaging centers respecting quantitative and qualitative requirements defined by international guidelines $[2,25]$ and that all data and results provided by the application of this protocol, including interval cancers, are stored on 
electronic databases. This will allow for future analyses of diagnostic performance and clinical efficacy on a multicenter scale.

\section{References}

1. Henderson TO, Amsterdam A, Bhatia S, et al (2010) Systematic review: surveillance for breast cancer in women treated with chest radiation for childhood, adolescent, or young adult cancer. Ann Intern Med 152:444-455

2. Sardanelli F, Boetes C, Borisch B, et al (2010) Magnetic resonance imaging of the breast: recommendations from the EUSOMA working group. Eur J Cancer 46:1296-1316

3. Ralleigh G, Given-Wilson R (2004) Breast cancer risk and possible screening strategies for young women following supradiaphragmatic irradiation for Hodgkin's disease. Clin Radiol 59:647-650

4. Allen SD, Wallis MG, Cooke R, Swerdlow AJ (2014) Radiologic features of breast cancer after mantle radiation therapy for Hodgkin disease: a study of 230 cases. Radiology 272:73-78

5. Saslow D, Boetes C, Burke W, et al; American Cancer Society Breast Cancer Advisory Group (2007) American Cancer Society guidelines for breast screening with MRI as an adjunct to mammography. CA Cancer J Clin 57:75-89

6. Lee $\mathrm{CH}$, Dershaw DD, et al (2010) Breast cancer screening with imaging: recommendations from the Society of Breast Imaging and the ACR on the use of mammography, breast MRI, breast ultrasound, and other technologies for the detection of clinically occult breast cancer. J Am Coll Radiol 7:18-27

7. Santoro F, Podo F, Sardanelli F (2014) MRI screening of women with hereditary predisposition to breast cancer: diagnostic performance and survival analysis. Breast Cancer Res Treat 147:685-687

8. Oeffinger KC, Ford JS, Moskowitz CS, et al (2009) Breast cancer surveillance practices among women previously treated with chest radiation for a childhood cancer. JAMA 301:404-414

9. Shapiro CL, Mauch PM (1992) Radiation-associated breast cancer after Hodgkin's disease: Risks and screening in perspective. J Clin Oncol 10:1662-1665

10. Yahalom J, Petrek JA, Biddinger PW, et al (1992) Breast cancer in patients irradiated for Hodgkin's disease: a clinical and pathologic analysis of 45 events in 37 patients. J Clin Oncol 10:1674-1681

11. Dershaw DD, Yahalom J, Petrek JA (1992) Breast carcinoma in women previously treated for Hodgkin disease: Mammographic evaluation. Radiology 184: 421-423

12. Wolden SL, Hancock SL, Carlson RW, et al (2000) Management of breast cancer after Hodgkin's disease. J Clin Oncol 18:765-772 
13. Diller L, Medeiros Nancarrow C, et al (2002) Breast cancer screening in women previously treated for Hodgkin's disease: a prospective cohort study. J Clin Oncol 20:2085-2091

14. Mariscotti G, Durando M, Ghione G, et al (2013) Breast cancer surveillance in patients treated by radiotherapy for Hodgkin's lymphoma. Radiol Med 118:401-414

15. Ng AK, Garber JE, Diller LR, et al (2013) Prospective study of the efficacy of breast magnetic resonance imaging and mammographic screening in survivors of Hodgkin lymphoma. J Clin Oncol 31:2282-2288

16. Tieu MT, Cigsar C, Ahmed S, et al (2014) Breast cancer detection among young survivors of pediatric Hodgkin lymphoma with screening magnetic resonance imaging. Cancer 120:2507-2513.

17. Sung JS, Lee CH, Morris EA, Oeffinger KC, Dershaw DD (2011) Screening breast MR imaging in women with a history of chest irradiation. Radiology 259:65-71

18. Freitas V, Scaranelo A, Menezes R, et al (2013) Added cancer yield of breast magnetic resonance imaging screening in women with a prior history of chest radiation therapy. Cancer 119:495-503

19. Cutuli B, Kanoun S, Tunon De Lara C, et al (2012) Breast cancer occurred after Hodgkin's disease: clinicopathological features, treatments and outcome: analysis of 214 cases Crit Rev Oncol Hematol 81:29-37

20. Mulder RL, Kremer LCM, Hudson MM et al (2013) Recommendations for breast cancer surveillance for female survivors of childhood, adolescent, and young adult cancer given chest radiation: a report from the International Late Effects of Childhood Cancer Guideline Harmonization Group. Lancet Oncol 14: e621-e629

21. Sardanelli F, Helbich TH (2012) Mammography: EUSOBI recommendations for women's information. Insights Imaging 3:7-10

22. Mann RM, Balleyguier C, Baltzer PA, et al; European Society of Breast Imaging (EUSOBI), with language review by Europa Donna-The European Breast Cancer Coalition (2015) Breast MRI: EUSOBI recommendations for women's information. Eur Radiol 25:3669-3678

23. Sardanelli F, Giuseppetti GM, Canavese G, et al (2008) Indications for breast magnetic resonance imaging. Consensus document "Attualità in senologia", Florence 2007. Radiol Med 113:1085-1095

24. American College of Radiology Breast Imaging Reporting and data System Atlas, $5^{\text {th }}$ edition (2013). Available at: http://www.acr.org/Quality-Safety/Resources/BIRADS. Accessed on April 18, 2016.

25. Wilson AR, Marotti L, Bianchi S, et al; EUSOMA-European Society of Breast Cancer Specialists (2013) The requirements of a specialist Breast Centre. Eur J Cancer 49:3579-3587 